\title{
ANÁLISE DE LIVROS
}

\section{Avaliação e Conduta nos Riscos Trombo e Aterogênico}

\author{
Editores: Tania Leme da Rocha Martinez \& Dayse Maria Lourenço \\ - São Paulo, Ed. Art Plus, 1996 - 164 páginas.
}

Livro ricamente ilustrado com tabelas, gráficos e figuras, traz conceitos importantes ao neurologista e clínico geral envolvido com a prevenção, diagnóstico e tratamento da doença vascular aterosclerótica. Particularmente importante para aqueles dedicados ao cuidado de pacientes com doença vascular cerebral.

Conceitos como trombogênese, a relação de fïbrinogênio e aterosclerose, aterogênese, expõem ao leitor a fisiopatologia do evento aterotrombótico, com objetividade e profundidade. Segue-se o metabolismo das lipoproteínas, com o papel das apolipoproteinas, VLDL, LDL e HDL, analisados sob o ponto de vista bioquímico. O papel da lipoproteína (a) ressalta sua associação com doenças cardiovasculares prematuras e sua ação no evento atero e trombogênico. O diagnóstico das dislipidemias é abordado de modo facilmente compreensível, com orientações sobre a coleta de amostras, metodologia do exame e valores de referência. A classificação das dislipidemias primárias e secundárias é exposta em tabelas permitindo consulta rápida. Em um livro de avaliação e conduta, o tratamento farmacológico das dislipidemias ganha especial atenção com revisão e análise de drogas, indicação de dietas, controle de fatores de risco, quem tratar?, como tratar?
Como crítica a este capítulo - e que poderia constar como apêndice em edição futura - sente-se faltit de tabelas ou orientações dietéticas quanto aos tipos de alimentos a serem evitados, substituídos ou ainda estimulados como redutores da absorção de colesterol. Outros assuntos não menos palpitantes como a relação das dislipidemias com a resistência à insulina, diabetes mellitus, e hipertensão arterial, complementam aspectos práticos do controle destes pacientes. A dislipidemia na mulher, enfocado em diferentes fases de sua vida hormonal também é abordado em capítulo especial. Aspectos da dislipidemia na infâncial, ressaltando a necessidade de avaliação precoce destes distúrbios, e as dislipidemias no idoso encerram a obral.

Alguns assuntos na Medicina são de conhecimento obrigatório não só por envolver direta ou indiretamente diferentes especialidades, mas por fazer parte de uma cultura que hoje transcende os limites acadêmicos ganhando páginas de revistas e jornais leigos. Estar atualizado nestes assuntos é imprescindível. O risco trombo e aterogênico é um destes assuntos.

Roberto de Magalhães Carneiro de Oliveira 


\section{Doença Cerebrovascular: Condutas - Volume I}

Editor: Rubens José Gagliardi - São Paulo, Geo-Gráfica e Editora, 1996 - 484 páginas.

Livro escrito por 51 profissionais de diferentes escolas médicas, de quase todo o país, mostra como a integração em torno de um ideal pode gerar bons frutos. Nascida sob os auspícios da Academia Brasileira de Neurologia, o que constituía um grupo de trabalho tornou-se a Sociedade Brasileira de Doenças Cerebrovasculares. Com a coordenaçāo do Dr. Rubens José Gagliardi, temas atuais nesta área da Neurologia foram revisados e analisados. A qualidade do texto, preservada a autonomia dos autores quanto à forma e conteúdo, é de grande riqueza, trazendo por vezes análises de um mesmo tema sob prismas diferentes. Em raros capítulos, autores procuraram expor mais seu trabalho pessoal do que apresentar uma conduta ao tema proposto, mas sem grande comprometimento da qualidade. Considero a obra leitura obrigatória aos iniciantes em Neurologia e àqueles que vêem o acidente vascular cerebral como algo que o tempo trata. Recomendo ainda a todos que pretendem atualizar-se no tema ou que buscam respostas para situações nem sempre fáceis de se encontrar uma conduta, como é comum nas doenças cerebrovasculares.

Roberto de Magalhães Carneiro de Oliveira

\section{Sono. Estudo Abrangente (2ª Edição)}

Editor: Rubens Reimão - São Paulo, Atheneu, 1996 - 442 páginas.

A 2a. Ediçāo do livro de sono, editado por Rubens Reimão, vem ampliada e com uma diversidade de autores bem maior que a la. Edição.

Neste livro, podemos observar capítulos escritos por autores europeus ao lado de capítulos escritos por latinoamericanos, além de capítulos mistos, com autores de palíses diversos. O Dr. Reimāo conseguiu reunir mais de meia centena de especialistas em sono, cobrindo os principais tópicos da área. As informaçōes contidas neste livro serão valiosas para os médicos que desejarem saber mais sobre patologias do sono, tanto nos aspectos de diagnóstico clínico e laboratorial, como nos aspectos terapêuticos.

Este volume inicia com uma boa discussão da fisiologia geral do sono, seguida por aspectos fisiológicos mais específicos dos ritmos circadianos, englobados no tema de cronobiologia. Os capítulos seguem numa sequência ordenada de títulos, passando de sono do neonato até sono na idade avançada. Alguns capítulos foram dedicados aos aspectos práticos do diagnóstico, tanto no laboratório como domiciliar, sendo este último caso uma conquista recente, possível devido aos novos recursos tecnológicos.

O tratamento de distúrbios respiratórios do sono é bem enfatizado, tendo sido dedicados alguns capítulos às diversas modalidades de tratamento das apnéias. Ao todo, temos 42 capítulos, que são lechados por um glossário de termos técnicos usados em descriçōes de sono.

Os médicos brasileiros têm, com este livro, um aliado precioso na compreensão dos distúrbios do sono.

Ademir Baptista Silva 